\title{
openheart Inflammation and echocardiographic parameters of ventricular hypertrophy in a cohort with preserved cardiac function
}

\author{
D Medenwald, ${ }^{1}$ S Dietz, ${ }^{2}$ D Tiller, ${ }^{1}$ A Kluttig, ${ }^{1}$ KH Greiser, ${ }^{3}$ H Loppnow, ${ }^{2}$ J Thiery, ${ }^{4}$ \\ S Nuding, ${ }^{2}$ M Russ, ${ }^{5}$ A Fahrig, ${ }^{2} \mathrm{~J} \mathrm{Haerting}^{1}{ }^{\mathrm{K}} \mathrm{K}$ Werdan ${ }^{2}$
}

To cite: Medenwald D, Dietz S, Tiller D, et al. Inflammation and echocardiographic parameters of ventricular hypertrophy in a cohort with preserved cardiac function. Open Heart 2014;1:e00004 doi:10.1136/openhrt-2013000004

Received 19 November 2013 Revised 1 January 2014 Accepted 5 January 2014

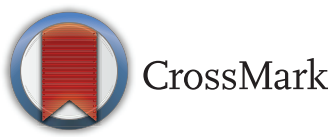

For numbered affiliations see end of article.

Correspondence to Dr Daniel Medenwald; daniel.medenwald@ukhalle.de

\section{ABSTRACT}

Objective: To investigate the association between inflammation and selective echocardiographic parameters (EP) characteristic for ventricular hypertrophy in cross-sectional and longitudinal population-based analyses.

Methods: Baseline (711 men, 659 women: 4583 years) and 4-year follow-up data (622 men, 540 women) of the prospective, population-based CARdiovascular disease, Living and Ageing in Halle (CARLA) study after exclusion of participants with cardiacvascular diseases were analysed. Inflammation parameters: soluble tumour necrosis factor receptor 1 (sTNF-R1), high-sensitivity $C$ reactive protein (hsCRP) and interleukin 6 (IL-6). EPs: left ventricular mass (LVM), left atrial systolic dimension (LADS), interventricular septum diameter (IVSD), posterior wall dimension (PWD), left ventricular diastolic diameter (LVDD), ejection fraction according to Teichholz (EF). For the longitudinal analyses baseline to follow-up differences were considered. Effect sizes were determined by using multiple linear regression and mixed models. Missing values were replaced by means of multiple imputations.

Results: Men had higher sTNF-R1 levels; means of hsCRP and IL-6 were similar in men and women. In multiple regression models, sTNF-R1 was associated with LADS $(1.4 \mathrm{~mm} / 1000 \mathrm{pg} / \mathrm{mL}$ sTNF-R $1,95 \% \mathrm{Cl}$ 0.6 to 2.1) in men. Respecting confounder hsCRP was associated with LVM $(5.2 \mathrm{~g} / 10 \mathrm{mg} / \mathrm{L} \mathrm{hsCRP,} 95 \% \mathrm{Cl}$ 1.6 to 8.8$)$, IVSD $(0.2 \mathrm{~mm} / 10 \mathrm{mg} / \mathrm{L} \mathrm{hsCRP,} 95 \% \mathrm{Cl}$ 0 to 0.3$)$ and PWD $(0.2 \mathrm{~mm} / 10 \mathrm{mg} / \mathrm{L} \mathrm{hsCRP,} 95 \%$ $\mathrm{Cl} 0.1$ to 0.3 ) in women, while there were no relevant effects in analysis of IL-6 in both sexes. The baseline to follow-up change in EPs was not relevantly associated with sTNF-R1, hsCRP or IL-6.

Conclusions: STNF-R1, hSCRP and IL-6 were inadequate predictors for structural changes of the heart at follow-up, while weak cross-sectional associations are restricted to certain EPs and depend on sex.

\section{INTRODUCTION}

The prognostic role of cytokines and their corresponding modulators, especially soluble tumour necrosis factor receptor 1
$(\mathrm{sTNF}-\mathrm{R} 1)^{1} \quad{ }^{2}$ and $\mathrm{C}$ reactive protein (CRP),${ }^{3-5}$ in the development of lethal outcomes of congestive systolic and diastolic heart failure (CHF) has been revealed previously. The value of cytokines in predicting death in patients with myocardial infarction was the subject of further studies. ${ }^{6} 7$ They found that higher levels of sTNF-R1, but not interleukin 6 (IL-6) and CRP, were associated with an increased risk of death. This is in contrast to the findings reported by Tan $e t a l^{8}$ who showed that IL-6 was an independent predictor of cardiovascular mortality. Further cross-sectional studies focused on the relationship between IL-6, sTNF-R1 and CRP, respectively, and left ventricular hypertrophy (LVH) in the general population ${ }^{9}$ and in asymptomatic hypertensive patients. ${ }^{10}$ The authors revealed a positive relationship between sTNF-R1 and LVH, but failed to find a similar effect for IL-6 and CRP, which was associated with LVH in another collective of asymptomatic participants with essential hypertension. ${ }^{11}$ Although there is evidence from experimental studies indicating the pathophysiological role of IL- 6 in the development of cardiac hypertrophy ${ }^{12}$ the impact of IL-6 on cardiac hypertrophy in humans remains controversial.

Summarising previous findings, sTNF-R1 was suggested to be of prognostic value for the course of disease in cardiac patients. The stability of sTNF-R1 makes it an easily assessable marker of the larger TNF system. ${ }^{13}$ Interestingly, the type 1 receptor of TNF- $\alpha$ is the origin of several pathways in the human heart, affecting cell metabolism, apoptosis and remodelling. ${ }^{2}$ The soluble form of this receptor is released from its membranebound component by different stimuli (eg, TNF- $\alpha$, lipopolysaccharides), and serves among other things as a ligand to 
TNF- $\alpha{ }^{14} 15$ The shedding of sTNF-R1 is increased in patients with heart failure, ${ }^{16}$ myocardial infarction ${ }^{17}$ and coronary artery disease. $^{18}$

Although the association between sTNF-R1 and CHF or LVH, respectively, has been examined previously in clinical populations, there is a substantial lack of studies examining the longitudinal association of inflammation with LVH assessed via echocardiographic parameters of ventricular wall thickness, dimensions and ejection fraction (EF) in cardiovascularly healthy participants. Therefore, the objectives of the current study were

1. To analyse the cross-sectional association of inflammation-especially sTNF-R1—with echocardiographic parameters related to ventricular hypertrophy in a cardiovascularly healthy population-based cohort, avoiding possible distractions due to pre-existing cardiac defects;

2. To assess the prognostic value of inflammation for changes in the parameters aforementioned in a 4-year period as a longitudinal analyses in this group of participants.

\section{METHODS}

\section{Study design and study population}

We used data from the CARdio-vascular disease, Living and Ageing in Halle (CARLA) study, which is a prospective population-based cohort study of the elderly general population of the city of Halle in eastern Germany. ${ }^{19}$ The CARLA cohort comprises 1779 participants (baseline response $64.1 \%$ ), aged $45-83$ years at baseline (967 men and 812 women). The baseline examination took place between December 2002 and January 2006. A multistep recruitment strategy aimed to achieve a high response rate. The percentage final response after subtracting exclusions (individuals who were deceased prior to the invitation, had moved away, or were unable to participate due to illness) was 64\%. From March 2007 until March 2010, the first 4-year follow-up examination was performed. The net sample (after exclusion of deceased or non-responding people) then comprised 1436 participants (86\% response), consisting of 790 men and 646 women aged between 50 and 87 years. The study participants underwent a detailed medical examination and a standardised, computer-assisted interview, which collected information on sociodemographic and socioeconomic variables, behavioural, biomedical and psychosocial factors, medical history and the use of medication within the preceding 7 days. Medication was automatically coded according to the Anatomical Therapeutic Chemical Classification System (ATC code). Additionally, an analysis of non-respondents was performed in order to assess non-response bias by obtaining information about prevalent diseases, and selected behavioural and sociodemographic factors. A more comprehensive account of the CARLA study can be found in Greiser et al. ${ }^{19}{ }^{20}$ All participants gave written informed consent. We included all patients without clinical and echocardiographic signs of CHF including elevated probrain natriuretic peptide. A more comprehensive account of the definition of CHF in the CARLA study can be found elsewhere. ${ }^{21}$ In short, CHF was defined as follows: presence of symptoms of CHF (oedema, fatigue and dyspnoea) and an NT-probrain natriuretic peptide (NT-proBNP) above $220 \mathrm{pg} / \mathrm{mL}$ or a reduced EF $(<50 \%$ according to the Teichholz et al $\mathrm{s}^{22}$ formula), or a left ventricular (LV) dimension index above $3.8 \mathrm{~cm} / \mathrm{m}^{2}$ in men and $3.7 \mathrm{~cm} / \mathrm{m}^{2}$ in women and echocardiographic parameters of diastolic dysfunction, which is in accordance with international guidelines. ${ }^{23}$ Additionally, we excluded all participants with a history of myocardial infarction and presence of cardiovascular diseases (history of stroke, history of vascular intervention-selfreported and subsequently physician approved). Thus, the final study sample comprised 711 men (256 excluded) and 659 women (153 excluded) at baseline and 622 men and 540 women at follow-up, while 52 men and 33 women primarily included in the study died between baseline and follow-up.

\section{Echocardiographic assessment}

At baseline, Doppler echocardiographic examinations were conducted and evaluated by a specially trained and certified physician. At follow-up, echocardiography was performed by a trained and certified study nurse, and subsequently the stored echocardiographic recordings were evaluated by a trained physician. All echocardiographers underwent the same dedicated study certification procedures. Assessing intraobserver variability for the M-mode examinations the mean observer bias varied between $0.3 \%$ and $3.8 \% \quad(2 * \mathrm{SD}$ between $15.3 \%$ and $27.7 \%$ ), while the interobserver variability ranged between $0.1 \%$ and $2.7 \% \quad(2 * \mathrm{SD}$ between $12.7 \%$ and $20.8 \%$ ). All echocardiographic examinations at baseline and follow-up were performed using the GE Vivid ultrasound system (GE Vivid 4 and 5 at baseline, GE vivid 5 at follow-up). To quantify the LV dimensions and function, we chose echocardiographic parameters (table 1) that are recommended by the guidelines for chamber quantification in echocardiography. ${ }^{24}$ We took only dimensional parameters, rather than volume parameters, into account. To calculate the left ventricular mass (LVM), we used the ASE-cube formula, which is in accordance with international guidelines. ${ }^{24}$ In addition, the size of the left ventricle was quantified according to the LV diastolic dimension (LVDD). The LV wall thickness was assessed by measuring the diastolic interventricular septum thickness (IVSD) and the diastolic thickness of the posterior wall (PWD). In order to examine the cross-sectional association of inflammation with the myocardial geometry more closely, we differentiated between participants with signs of concentric remodelling and participants without such changes. According to Lang et $a l^{24}$ concentric remodelling was defined based on the relative posterior wall thickness (RPWD), which was calculated by the formula RPWD= 
Table 1 Baseline characteristics

\begin{tabular}{|c|c|c|c|c|c|c|c|c|}
\hline \multirow[b]{3}{*}{ Miscellaneous } & \multicolumn{4}{|c|}{ Baseline } & \multicolumn{4}{|c|}{ Follow-up } \\
\hline & \multicolumn{2}{|c|}{$\overline{\text { Men }}$} & \multicolumn{2}{|c|}{ Women } & \multicolumn{2}{|l|}{ Men } & \multicolumn{2}{|c|}{ Women } \\
\hline & $\overline{\mathbf{N}}$ & Mean $(95 \% \mathrm{Cl})$ & $\overline{\mathbf{N}}$ & Mean $(95 \% \mathrm{Cl})$ & $\overline{\mathbf{N}}$ & Mean $(95 \% \mathrm{Cl})$ & $\overline{\mathbf{N}}$ & Mean $(95 \% \mathrm{Cl})$ \\
\hline Age (years) & 711 & 62 (61 to 63$)$ & 659 & 62 (61 to 63$)$ & 621 & 66 (65 to 66$)$ & 540 & 65 [64 to 66$]$ \\
\hline $\operatorname{BSA}\left(\mathrm{m}^{2}\right)$ & 711 & 1.98 (1.98 to 1.98$)$ & 659 & 1.75 (1.74 to 1.77$)$ & 618 & 1.98 (1.96 to 1.99$)$ & 534 & $1.75[1.73$ to 1.76$]$ \\
\hline $\mathrm{AMP}(\mathrm{mm} \mathrm{Hg})$ & 711 & $106.57(105.67$ to 107.47$)$ & 659 & $102.01(101.02$ to 103.01$)$ & 619 & $100.06(99.12$ to 101.01$)$ & 535 & 97.3 [96.32 to 98.28$]$ \\
\hline BMI $\left(\mathrm{kg} / \mathrm{m}^{2}\right)$ & 711 & 27.67 (27.47 to 27.87$)$ & 659 & $27.76(27.5$ to 28.01$)$ & 618 & 27.79 (27.57 to 28.02$)$ & 534 & 27.74 [27.44 to 28.06$]$ \\
\hline \multicolumn{9}{|c|}{ Echocardiographic parameters } \\
\hline LV mass $(g)^{*}$ & 691 & 228.64 (224.49 to 232.86 ) & 460 & 220.77 (215.99 to 225.65 ) & 460 & 220.77 (215.99 to 225.65 ) & 425 & $166.34[162.71$ to 170.05$]$ \\
\hline $\operatorname{PWD}(\mathrm{mm})^{*}$ & 692 & $11.9(11.79$ to 12.02$)$ & 463 & $11.1(10.92$ to 11.28$)$ & 463 & $11.1(10.92$ to 11.28$)$ & 425 & $10[9.82$ to 10.18$]$ \\
\hline $\operatorname{IVSD}(\mathrm{mm})^{*}$ & 695 & $11.87(11.75$ to 12$)$ & 462 & $11.63(11.44$ to 11.81$)$ & 462 & $11.63(11.44$ to 11.81$)$ & 428 & $10.57[10.4$ to 10.74$]$ \\
\hline $\operatorname{LAD}(\mathrm{mm})^{*}$ & 683 & 40.08 (39.73 to 40.43$)$ & 579 & $40.92(40.53$ to 41.31$)$ & 579 & $40.92(40.53$ to 41.31$)$ & 506 & $37.81[37.41$ to 38.21$]$ \\
\hline LVDd $(\mathrm{mm})^{*}$ & 693 & 49.39 (48.88 to 49.9$)$ & 464 & 50.17 (49.66 to 50.68$)$ & 464 & 50.17 (49.66 to 50.68$)$ & 426 & 45.85 [45.36 to 46.35$]$ \\
\hline $\mathrm{EF}(\%)$ & 690 & $62.78(62.16$ to 63.4$)$ & 458 & 65.54 (64.67 to 66.43$)$ & 458 & 65.54 (64.67 to 66.43$)$ & 422 & $67.93[67.03$ to 68.84$]$ \\
\hline \multicolumn{9}{|l|}{ Blood parameters } \\
\hline TNF-R1 (pg/mL) & 672 & $1122.62(1093.02$ to 1153.03$)$ & 614 & 1021.97 (994.12 to 1050.6$)$ & & & & \\
\hline hsCRP (mg/L) & 681 & $1.67(1.54$ to 1.8$)$ & 642 & 1.85 (1.7 to 2.01$)$ & 619 & 1.84 (1.71 to 1.99$)$ & 531 & $1.85[1.7$ to 2.01$]$ \\
\hline IL-6 (pg/mL) & 672 & 1.99 (1.83 to 2.17$)$ & 614 & 1.8 (1.65 to 1.97$)$ & & & & \\
\hline Creatinine $(\mu \mathrm{mol} / \mathrm{L})$ & 708 & 78.41 (77.33 to 79.52$)$ & 659 & 63.34 (62.48 to 64.22 ) & 619 & 82.37 (80.82 to 83.96$)$ & 531 & 66.74 [65.66 to 67.83$]$ \\
\hline $\mathrm{HDL}(\mathrm{mmol} / \mathrm{l})$ & 690 & 3.11 (3.04 to 3.17 ) & 656 & 3.32 (3.25 to 3.39$)$ & 606 & 3.05 (2.98 to 3.12$)$ & 529 & $3.36[3.28$ to 3.44$]$ \\
\hline $\mathrm{HbA1c}(\%)$ & 708 & 5.67 (5.61 to 5.73 ) & 659 & 5.64 (5.59 to 5.7$)$ & 619 & 5.79 (5.73 to 5.84$)$ & 531 & 5.79 [5.73 to 5.84$]$ \\
\hline \multicolumn{9}{|l|}{ Numeric values } \\
\hline Median $\mathrm{n}$ of medication & 711 & 4 & 659 & 4 & 619 & 4 & 535 & 4 \\
\hline
\end{tabular}

Means are displayed as geometric means with the respecting $95 \%$ confidence limits.

${ }^{*}$ Adjusted for body surface area.

AMP, Arterial mean pressure; BMI, body mass index; BSA, Body surface area; CRP, high-sensitivity C reactive protein; EF, left ventricular ejection fraction; HDL, high-density lipoproteinhs; IL,

interleukin 6; IVSD, interventricle septum diameter; LAD, left atrial diastolic diameter; LV, left ventricular mass; LVDd, left ventricular end-diastolic dimension; PWD, posterior wall dimension;

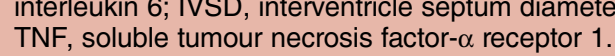


$(2 \times$ PWD $) /$ LVDD $^{24}$ Finally, an RPWD above 0.42 was considered a concentrically altered LV. The cardiac output as a functional parameter was measured by the EF according to Teichholz et $a l^{22}$ We added the systolic dimension of the left atrium (LADS) to our analysis, as this parameter was previously found to be related to cardiac risk. $^{24}$

\section{Laboratory measurements}

Blood samples were taken after a supine rest of $30 \mathrm{~min}$ at baseline and at follow-up. At baseline the parameters of sTNF-R1, high-sensitivity CRP (hsCRP) and IL-6 were assessed, while hsCRP was measured at follow-up as well.

STNF-R1 and IL-6 were analysed by the Department of Medicine III, University Clinics Halle (Saale). After $10 \mathrm{~min}$ centrifugation $\left(20^{\circ} \mathrm{C}, 1500 \mathrm{rpm}, \mathrm{Acc}=9\right.$, Dcc $\left.=3\right)$, the plasma was collected and stored at $-80^{\circ} \mathrm{C}$. Cytokines were assessed using commercially available sandwich ELISAs (IL-6, Opteia, BD Biosciences, Heidelberg, Germany; TNF-R1, Boehringer Mannheim, Mannheim, Germany).

The determination of hsCRP was undertaken by the Institute of Laboratory Medicine, Clinical Chemistry and Molecular Diagnostics at the Leipzig University Clinics. The laboratory has been accredited according to the accreditation norms ISO 15180 and ISO 17025. Serum hsCRP levels were measured using a high-sensitivity immunoturbidimetric method (CRP (Latex) HS, Roche, Mannheim, Germany) on a Hitachi autoanalyser (Roche Diagnostics Mannheim, Germany).

\section{Statistical methods}

All analyses were performed separately for men and women. Descriptive results are displayed as geometric means to illustrate the distribution of echocardiographic and inflammation parameters in the study population.

To assess the association of sTNF-R1, hsCRP and IL-6 (each as an independent variable) with all six echocardiographic parameters in a multivariate approach we used mixed models with an unstructured covariance matrix respecting echocardiographic parameters as a fixed effect. These analyses were separately conducted for sTNF-R1, hsCRP and IL-6, men and women, and the cross-sectional and longitudinal analyses, respectively (statistical results given in tables 2-4). Parameters were entered in the mixed model after standardisation of all included dependent and independent parameters (mean $=0, \mathrm{SD}=1$ ) making the association across all echocardiographic parameters comparable between analyses. In addition, single regression coefficients and respective 95\% CIs (association of each inflammation parameter with each echocardiographic parameter) were calculated by means of univariate linear robust regression models. Models were adjusted for arterial mean pressure, body surface area, age, medication, glycated haemoglobin (HbAlc), low-density lipoprotein and creatinine clearance. As medication, we considered antihypertensive drugs (ATC codes: C02/C03/C07/C08/C09), cardiac glycosides (ATC code: C01A) and lipid-lowering medication (ATC code: C10). In the longitudinal regression analysis, we used the difference in echocardiographic values between baseline and follow-up as outcome without consideration of baseline echocardiographic values as a further covariate. ${ }^{25}$ The idea beyond such a longitudinal analysis is to check for associations of a change in one parameter over time (from baseline to follow-up), depending on an explanatory variable, which influences the course of the dependent parameter. Possible differences in the blood level of inflammatory parameters between participants with signs of a concentrically altered LV wall thickness compared with participants without such signs were checked by performing a Mann-Whitney U test. Echocardiographic parameters adjusted for body surface area are specified in the descriptive statistics. Finally, the adequacy of the considered regression models was assumed when the residuals were normally distributed, which was tested via a $\mathrm{Q}-\mathrm{Q}$ plot and Cook's distance, which was required to be below one (achieved for all conducted tests).

Missing values were replaced using the method of multiple imputation, which was previously found to cause little $\operatorname{bias}^{26}$ (see online supplementary appendix for further details). Deviations of the results between multiple imputations and the complete case analysis were compared in a sensitivity analysis, which is given in the appendix. A further sensitivity analysis was performed after exclusion of participant with the presence of selfreported and physician evaluated chronic diseases related to inflammation (cancer, rheumatoid arthritis, gout, liver disease, chronic kidney disease with a glomerular filtration rate below $30 \mathrm{~mL} / \mathrm{min}$ ).

The level of significance was taken as $\alpha=0.05$, and consequently we report the $95 \%$ confidence limits. All statistical analyses and data management were performed using SAS, V.9.3 (SAS Inc, Cary, North Carolina, USA).

\section{RESULTS \\ Study population}

In the final sample, the mean age at baseline of male and female participants was 62 years (95\% CI 61 to 63 ; table 1). We observed a higher EF but lower echocardiographic dimension and LV wall thickness parameters in women compared to men. While men showed a higher concentration of plasma sTNF-R1 (table 1), no considerable differences in plasma levels of hsCRP and IL-6 between sexes could be observed. At follow-up, our data indicated a decrease in LVM and an increase in EF, while there were no relevant changes in the mean of further echocardiographic parameters.

\section{Cross-sectional association of inflammation and echocardiographic parameters}

Soluble tumour necrosis factor receptor 1

Most of the participants had blood levels of sTNF-R1 between 500 and $2000 \mathrm{pg} / \mathrm{mL}$, although $5.65 \%$ of men 
Table 2 Estimates of the regression analysis of STNF-R1

\begin{tabular}{|c|c|c|c|c|c|c|c|c|}
\hline \multirow[b]{3}{*}{ sTNF-R1 } & \multicolumn{4}{|l|}{ Men } & \multicolumn{4}{|l|}{ Women } \\
\hline & \multicolumn{2}{|l|}{ Core } & \multicolumn{2}{|l|}{ Adjusted } & \multicolumn{2}{|l|}{ Core } & \multicolumn{2}{|l|}{ Adjusted } \\
\hline & $\bar{\beta}(95 \% \mathrm{Cl})$ & p Value & $\overline{\beta(95 \% ~ C l)}$ & p Value & $\overline{\beta(95 \% ~ C l)}$ & p Value & $\overline{\beta(95 \% ~ C l)}$ & p Value \\
\hline Cross sectional* & $0.11(0.07$ to 0.14$)$ & $<0.0001$ & $0.06(0.02$ to 0.1$)$ & 0.0038 & $0.15(0.1$ to 0.2$)$ & $<0.0001$ & $0.04(-0.01$ to 0.09$)$ & 0.0998 \\
\hline LVM (g) & 13.8 (5.6 to 21.9$)$ & 0.0011 & $5.7(-2.7$ to 14$)$ & 0.1820 & 22.8 (14 to 31.6$)$ & $<0.0001$ & $3.5(-4.5$ to 11.5$)$ & 0.3932 \\
\hline PWD (mm) & $0.6(0.4$ to 0.8$)$ & $<0.0001$ & $0.3(0$ to 0.5$)$ & 0.0231 & 1 (0.8 to 1.3$)$ & $<0.0001$ & $0.3(0.1$ to 0.6$)$ & 0.0121 \\
\hline IVSD (mm) & 0.6 (0.3 to 0.8$)$ & $<0.0001$ & $0.2(-0.1$ to 0.4$)$ & 0.1614 & 1 (0.7 to 1.3$)$ & $<0.0001$ & 0.3 (0 to 0.6$)$ & 0.0267 \\
\hline LADS (mm) & 2.1 (1.3 to 2.8$)$ & $<0.0001$ & $1.4(0.6$ to 2.1$)$ & 0.0010 & 2.5 (1.7 to 3.4$)$ & $<0.0001$ & $0(-0.9$ to 0.8$)$ & 0.9755 \\
\hline LVDD (mm) & $0(-0.8$ to 0.8$)$ & 0.9796 & $0.2(-0.7$ to 1$)$ & 0.6835 & $0(-0.9$ to 0.9$)$ & 0.9925 & $-0.7(-1.6$ to 0.2$)$ & 0.1532 \\
\hline $\mathrm{EF}(\%)$ & $-0.3(-1.4$ to 0.9$)$ & 0.6442 & $-0.1(-1.4$ to 1.2$)$ & 0.8885 & $0.5(-0.8$ to 1.7$)$ & 0.4666 & $0.6(-0.9$ to 2.1$)$ & 0.4003 \\
\hline Longitudinal $^{*}$ & $-0.44(-0.92$ to 0.03$)$ & 0.0675 & $-0.02(-0.08$ to 0.04$)$ & 0.4641 & $0.18(-0.34$ to 0.7$)$ & 0.4873 & $0.44(-0.14$ to 1.02$)$ & 0.1320 \\
\hline LVM (g) & $-8.1(-19.3$ to 3.1$)$ & 0.1568 & $-3.3(-16.4$ to 9.8$)$ & 0.6181 & $-1(-11$ to 9.1$)$ & 0.8455 & $5.8(-6.1$ to 17.7$)$ & 0.3361 \\
\hline PWD (mm) & $-0.4(-0.8$ to 0.1$)$ & 0.1031 & $-0.2(-0.7$ to 0.3$)$ & 0.4765 & $-0.3(-0.8$ to 0.2$)$ & 0.3043 & $-0.1(-0.7$ to 0.5$)$ & 0.6642 \\
\hline IVSD (mm) & $-0.1(-0.6$ to 0.3$)$ & 0.6007 & $0.1(-0.4$ to 0.7$)$ & 0.5619 & $-0.3(-0.8$ to 0.2$)$ & 0.2469 & $0(-0.6$ to 0.6$)$ & 0.9177 \\
\hline LADS (mm) & $0.1(-0.8$ to 1$)$ & 0.8342 & $0.1(-0.9$ to 1.1$)$ & 0.8406 & $0.6(-0.3$ to 1.5$)$ & 0.2162 & $0.7(-0.4$ to 1.7$)$ & 0.2073 \\
\hline LVDD (mm) & $-0.2(-1.4$ to 1.1$)$ & 0.7971 & $-0.3(-1.7$ to 1.1$)$ & 0.6880 & $1.5(0.1$ to 2.8$)$ & 0.0340 & $1.7(0.1$ to 3.3$)$ & 0.0357 \\
\hline EF (\%) & $-1.3(-3.4$ to 0.7$)$ & 0.2084 & $-1.7(-4.1$ to 0.6$)$ & 0.1501 & $-0.5(-3.1$ to 2$)$ & 0.6742 & $-1(-3.9$ to 1.9$)$ & 0.4931 \\
\hline
\end{tabular}

Estimates of the longitudinal analyses mean the absolute baseline to follow-up difference of echocardiographic parameters.

Adjusted for arterial mean pressure, body surface area, age, medication, $\mathrm{HbA1c}$, LDL and creatinine clearance.

*(grey-shaded line)=results from mixed models estimating the association of inflammation parameter across all six echocardiographic parameters in the cross-sectional, and longitudinal analyses, respectively. Estimates were standardised (mean=0, $\mathrm{SD}=1$ ).

EF, ejection fraction; HbA1c, glycated haemoglobin; IL-6, interleukin 6; IVSD, interventricle septum diameter; LADS, left atrial diastolic diameter; LVDD, left ventricular end-diastolic dimension; LDL, low-density lipoprotein; LVM, left ventricular mass; PWD, posterior wall dimension; sTNF-R1, soluble tumour necrosis factor- $\alpha$ receptor 1. 
Table 3 Estimates of the regression analysis of hsCRP

\begin{tabular}{|c|c|c|c|c|c|c|c|c|}
\hline \multirow[b]{3}{*}{ hsCRP } & \multicolumn{4}{|l|}{ Men } & \multicolumn{4}{|l|}{ Women } \\
\hline & \multicolumn{2}{|l|}{ Core } & \multicolumn{2}{|l|}{ Adjusted } & \multicolumn{2}{|l|}{ Core } & \multicolumn{2}{|l|}{ Adjusted } \\
\hline & $\beta(95 \% \mathrm{Cl})$ & p Value & $\beta(95 \% \mathrm{Cl})$ & p Value & $\beta(95 \% \mathrm{Cl})$ & p Value & $\overline{\beta(95 \% ~ C l)}$ & p Value \\
\hline Cross sectional $^{*}$ & $0.02(-0.03$ to 0.06$)$ & 0.5024 & $0.02(-0.03$ to 0.06$)$ & 0.4821 & 0.04 (0.02 to 0.07$)$ & 0.0004 & $0.03(0.01$ to 0.05$)$ & 0.0133 \\
\hline $\operatorname{LVM}(\mathrm{g})$ & $1(-8.7$ to 10.6$)$ & 0.8442 & $-1.9(-10.2$ to 6.3$)$ & 0.6449 & 12.7 (3.6 to 21.8$)$ & 0.0064 & $5.2(1.6$ to 8.8$)$ & 0.0051 \\
\hline PWD (mm) & 0.2 (0 to 0.5$)$ & 0.0800 & $0.1(-0.2$ to 0.3$)$ & 0.5006 & 0.5 (0.2 to 0.9$)$ & 0.0012 & $0.2(0.1$ to 0.3$)$ & 0.0013 \\
\hline IVSD (mm) & $0.2(-0.1$ to 0.5$)$ & 0.1788 & $0.1(-0.2$ to 0.3$)$ & 0.5734 & $0.5(0.2$ to 0.8$)$ & 0.0016 & $0.2(0$ to 0.3$)$ & 0.0072 \\
\hline LADS (mm) & $0.7(-0.2$ to 1.7$)$ & 0.1156 & $0.4(-0.4$ to 1.3$)$ & 0.3073 & $0.8(0.1$ to 1.5$)$ & 0.0337 & $0.2(-0.2$ to 0.6$)$ & 0.2310 \\
\hline LVDD (mm) & $-0.2(-1.1$ to 0.7$)$ & 0.6415 & $-0.4(-1.3$ to 0.5$)$ & 0.3904 & $0.1(-0.4$ to 0.7$)$ & 0.5882 & $-0.2(-0.6$ to 0.3$)$ & 0.4811 \\
\hline EF (\%) & $-0.3(-1.6$ to 1.1$)$ & 0.6807 & $-0.3(-1.6$ to 1.1$)$ & 0.6846 & $-0.3(-1.1$ to 0.6$)$ & 0.5447 & $-0.3(-1$ to 0.4$)$ & 0.4336 \\
\hline Longitudinal $^{*}$ & $-0.01(-0.56$ to 0.55$)$ & 0.9851 & $-0.01(-0.06$ to 0.05$)$ & 0.9289 & $-0.12(-0.75$ to 0.52$)$ & 0.7102 & $-0.01(-0.07$ to 0.06$)$ & 0.8031 \\
\hline LVM (g) & $3.2(-9.1$ to 15.6$)$ & 0.6043 & $3.4(-9.4$ to 16.2$)$ & 0.5954 & $-3(-13.8$ to 7.9$)$ & 0.5888 & $-1.4(-12.5$ to 9.7$)$ & 0.8064 \\
\hline PWD (mm) & $-0.2(-0.7$ to 0.3$)$ & 0.4190 & $-0.2(-0.6$ to 0.3$)$ & 0.4952 & $-0.3(-0.9$ to 0.2$)$ & 0.2418 & $-0.2(-0.8$ to 0.3$)$ & 0.4197 \\
\hline IVSD (mm) & $0.1(-0.4$ to 0.5$)$ & 0.8090 & $0.1(-0.4$ to 0.5$)$ & 0.8327 & $-0.2(-0.7$ to 0.3$)$ & 0.4724 & $-0.1(-0.6$ to 0.4$)$ & 0.7357 \\
\hline LADS (mm) & $0.8(-0.2$ to 1.8$)$ & 0.1149 & $0.6(-0.3$ to 1.6$)$ & 0.1928 & $1.1(0.1$ to 2.1$)$ & 0.0376 & $0.9(-0.1$ to 2$)$ & 0.0878 \\
\hline LVDD (mm) & 0.7 (-0.6 to 2$)$ & 0.3191 & $0.6(-0.7$ to 2$)$ & 0.3687 & 0.5 (-1.1 to 2$)$ & 0.5424 & 0.4 (-1.2 to 2$)$ & 0.6083 \\
\hline $\mathrm{EF}(\%)$ & $-1.5(-3.5$ to 0.6$)$ & 0.1559 & $-1.5(-3.6$ to 0.6$)$ & 0.1491 & $-0.3(-3$ to 2.4$)$ & 0.8181 & $-0.2(-2.9$ to 2.6$)$ & 0.9117 \\
\hline
\end{tabular}

-1.5 ( -3.5 to 0.6$)$

0.1559

$-1.5(-3.6$ to 0.6$)$

0.1491

$-0.3(-3$ to 2.4$)$

Adjusted for arterial mean pressure, body surface area, age, medication, HbA1c, LDL and creatinine clearance.

*(grey shaded line)=results from mixed models estimating the association of inflammation parameter across all six echocardiographic parameters in the cross-sectional, and longitudinal analyses, respectively. Estimates were standardised (mean $=0, S D=1$ ).

hsCRP, high-sensitivity C reactive protein, EF, ejection fraction; IL-6, interleukin 6; IVSD, interventricle septum diameter; LADS, left atrial diastolic diameter; LVDD, left ventricular end-diastolic

dimension; LDL, low-density lipoprotein; LVM, left ventricular mass; PWD, posterior wall dimension. 
Table 4 Estimates of the regression analysis of IL-6

\begin{tabular}{|c|c|c|c|c|c|c|c|c|}
\hline \multirow[b]{3}{*}{ IL-6 } & \multicolumn{4}{|l|}{ Men } & \multicolumn{4}{|l|}{ Women } \\
\hline & \multicolumn{2}{|l|}{ Core } & \multicolumn{2}{|l|}{ Adjusted } & \multicolumn{2}{|l|}{ Core } & \multicolumn{2}{|l|}{ Adjusted } \\
\hline & $\bar{\beta}(95 \% \mathrm{CI})$ & p Value & B (95\% CI) & $\overline{p \text { Value }}$ & $\overline{\beta(95 \% ~ C l)}$ & $\bar{p}$ Value & $\bar{\beta}(95 \% \mathrm{CI})$ & $\overline{p \text { Value }}$ \\
\hline Cross sectional* & $-0(-0.05$ to 0.05$)$ & 0.9471 & $-0.01(-0.05$ to 0.04$)$ & 0.7432 & $0.08(-0.02$ to 0.17$)$ & 0.1031 & $0.07(-0.01$ to 0.14$)$ & 0.0834 \\
\hline LVM (g) & $2.1(-2.3$ to 6.5$)$ & 0.3321 & $-0.3(-1.9$ to 1.2$)$ & 0.6782 & $2(-1.5$ to 5.5$)$ & 0.2516 & $0.3(-3$ to 3.7$)$ & 0.8377 \\
\hline PWD (mm) & 0.1 (0 to 0.2$)$ & 0.0761 & $0.1(0$ to 0.2$)$ & 0.0794 & $0.1(0$ to 0.3$)$ & 0.0956 & 0.1 (0 to 0.2$)$ & 0.1962 \\
\hline IVSD (mm) & 0.1 (0 to 0.2$)$ & 0.1178 & $0(-0.1$ to 0.2$)$ & 0.5380 & $0.1(-0.1$ to 0.2$)$ & 0.2309 & 0.1 (0 to 0.1$)$ & 0.1552 \\
\hline LADS (mm) & $0.3(-0.1$ to 0.6$)$ & 0.0984 & $0.1(-0.1$ to 0.3$)$ & 0.5914 & $0.2(-0.3$ to 0.6$)$ & 0.4621 & $0.2(-0.2$ to 0.5$)$ & 0.2764 \\
\hline LVDD (mm) & $-0.1(-0.5$ to 0.3$)$ & 0.4617 & $-0.1(-0.5$ to 0.3$)$ & 0.7001 & -0.1 ( -0.3 to 0.2$)$ & 0.6394 & $-0.1(-0.4$ to 0.1$)$ & 0.2281 \\
\hline $\mathrm{EF}(\%)$ & $-0.1(-0.6$ to 0.3$)$ & 0.5474 & $-0.3(-0.5$ to 0$)$ & 0.0468 & $0(-0.7$ to 0.8$)$ & 0.9634 & $0.1(-0.4$ to 0.7$)$ & 0.6011 \\
\hline Longitudinal* & $0.05(-0.46$ to 0.55$)$ & 0.8498 & $0.01(-0.04$ to 0.06$)$ & 0.7329 & $-0.67(-1.44$ to 0.11$)$ & 0.0915 & $-0.06(-0.14$ to 0.01$)$ & 0.1070 \\
\hline LVM (g) & $-3.2(-8.3$ to 1.9$)$ & 0.2067 & $-1.7(-7.4$ to 4$)$ & 0.5384 & $-0.1(-4.8$ to 4.5$)$ & 0.9562 & $-0.9(-3.7$ to 1.9$)$ & 0.5319 \\
\hline PWD (mm) & $-0.2(-0.3$ to 0$)$ & 0.1101 & $-0.1(-0.4$ to 0.1$)$ & 0.2244 & $-0.1(-0.2$ to 0.1$)$ & 0.2689 & $-0.1(-0.2$ to 0.1$)$ & 0.2506 \\
\hline IVSD (mm) & $0(-0.2$ to 0.2$)$ & 0.8388 & $0.1(-0.1$ to 0.2$)$ & 0.3519 & $0(-0.3$ to 0.2$)$ & 0.6943 & $-0.1(-0.2$ to 0.1$)$ & 0.3989 \\
\hline LADS (mm) & $0(-0.4$ to 0.3$)$ & 0.7980 & $0(-0.1$ to 0.2$)$ & 0.6791 & $-0.1(-0.7$ to 0.4$)$ & 0.6510 & $-0.4(-0.7$ to 0$)$ & 0.0656 \\
\hline LVDD (mm) & $-0.1(-0.3$ to 0.2$)$ & 0.5102 & $-0.1(-0.3$ to 0.1$)$ & 0.4871 & $0.1(-0.2$ to 0.5$)$ & 0.4453 & $0.1(\mathrm{I}-0.2$ to 0.5$)$ & 0.5017 \\
\hline $\mathrm{EF}(\%)$ & $0(-0.8$ to 0.8$)$ & 0.9729 & $0.2(-0.6$ to 1$)$ & 0.6496 & $0(-0.7$ to 0.7$)$ & 0.9795 & $0(-0.6$ to 0.7$)$ & 0.9485 \\
\hline
\end{tabular}

Estimates of the longitudinal analyses mean the absolute baseline to follow-up difference of echocardiographic parameters.

Adjusted for arterial mean pressure, body surface area, age, medication, HbA1c, LDL and creatinine clearance.

${ }^{*}$ (grey-shaded line)=results from mixed models estimating the association of inflammation parameter across all six echocardiographic parameters in the cross-sectional, and longitudinal analyses, respectively. Estimates were standardised (mean=0, $\mathrm{SD}=1$ ).

EF, ejection fraction; HbA1c, glycated haemoglobin; IL-6, interleukin 6; IVSD, interventricle septum diameter; LADS, left atrial diastolic diameter; LVDD, left ventricular end-diastolic dimension

LDL, low-density lipoprotein; LVM, left ventricular mass; PWD, posterior wall dimension. 
and $3.09 \%$ of women showed even higher values (see online supplementary figure A1). The estimates obtained from mixed models (covariate adjusted) respecting all six echocardiographic parameters indicated an overall association of sTNF-R1 with echocardiography in men, but not in women. The univariate analysis of echocardiographic values as a function of inflammatory parameters revealed a relevant unadjusted association of sTNF-R1 with LVM, IVSD, PWD and LADS (table 2). Nevertheless, after the models were adjusted for the considered covariates, the regression coefficients decreased considerably. A medium effect size remained only when LADS (1.4 mm/ $1000 \mathrm{pg} / \mathrm{mL}$ sTNF-R1, 95\% CI 0.6 to 2.1 ) was the outcome in men, while the association of sTNF-R1 with PWD is of minor clinical relevance. The regression analysis of EF as a functional parameter revealed no relevant association with sTNF-R1 (see online supplementary figure A2). Consistent with the findings of the regression analysis of LVDD and PWD, the differentiation between concentric remodelling and ordinary/eccentric myocardial tissue (figures 1 and 2, see the online supplementary appendix for the results across both sexes) indicated that men and women with signs of concentric alterations had considerably higher blood levels of sTNF-R1.

\section{High-sensitivity $\mathrm{C}$ reactive protein}

The majority of the study population had plasma hsCRP levels below $10 \mathrm{mg} / \mathrm{L}$ (see online supplementary figure A1). A general association of hsCRP with echocardiographic parameters could only be found in women, which was mainly due to low statistical variance $(0.03$, $95 \%$ CI 0.01 to 0.05 ), while the estimate itself was lower than in the case of sTNF-R1. The multivariate analysis revealed lower effect estimates in men than in women. When covariates were taken into account, hsCRP was positively associated with LVM $(5.2 \mathrm{~g} / 10 \mathrm{mg} / \mathrm{L}$ hsCRP, 95\% CI 1.6 to 8.8$)$, PWD $(0.2 \mathrm{~mm} / 10 \mathrm{mg} / \mathrm{L}$ hsCRP, $95 \%$ CI 0.1 to 0.3$)$ and IVSD $(0.2 \mathrm{~mm} / 10 \mathrm{mg} / \mathrm{L}$ hsCRP, $95 \%$ CI 0 to 0.3$)$ in female participants, though the estimates
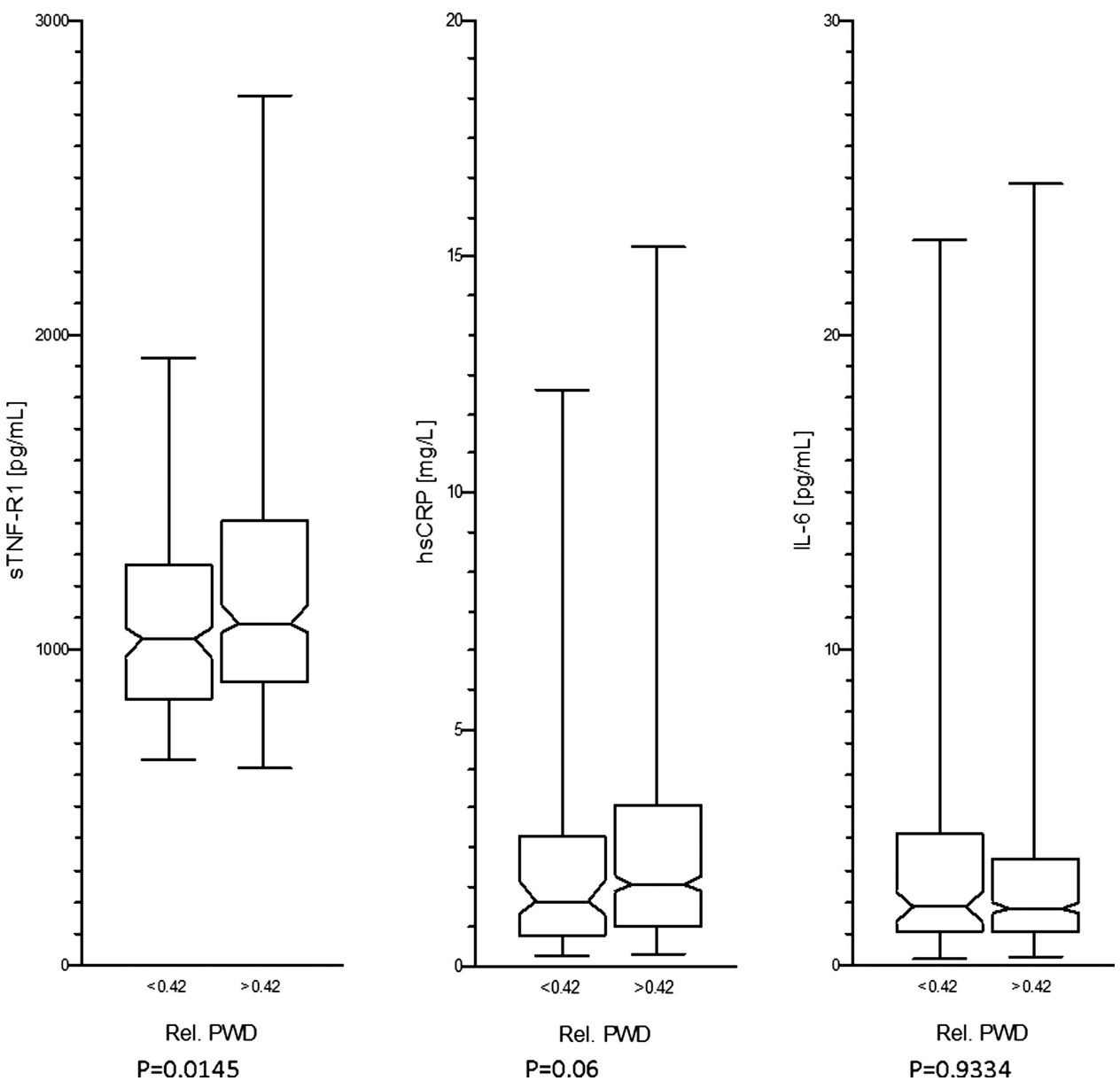

Figure 1 Box plot comparing inflammation parameters in men with (RPWD<0.42) and without (RPWD>0.42) signs of concentric hypertrophy. Lower and upper whiskers display the $2 \%$ and $98 \%$ quintiles, respectively. Notches display the $95 \% \mathrm{Cl}$ of the median (shortened horizontal line). The box represents participants between $25 \%$ and $75 \%$ quintiles. $p$ Values refer to group comparison (RPWD $<0.42$ and RPWD $>0.42$ ) by means of a Mann-Whitney $U$ test. hsCRP, high-sensitivity $C$ reactive protein; IL-6, interleukin 6; RPWD, relative posterior wall dimension of the left ventricle; sTNF-R1, soluble tumour necrosis factor- $\alpha$ receptor 1 . 


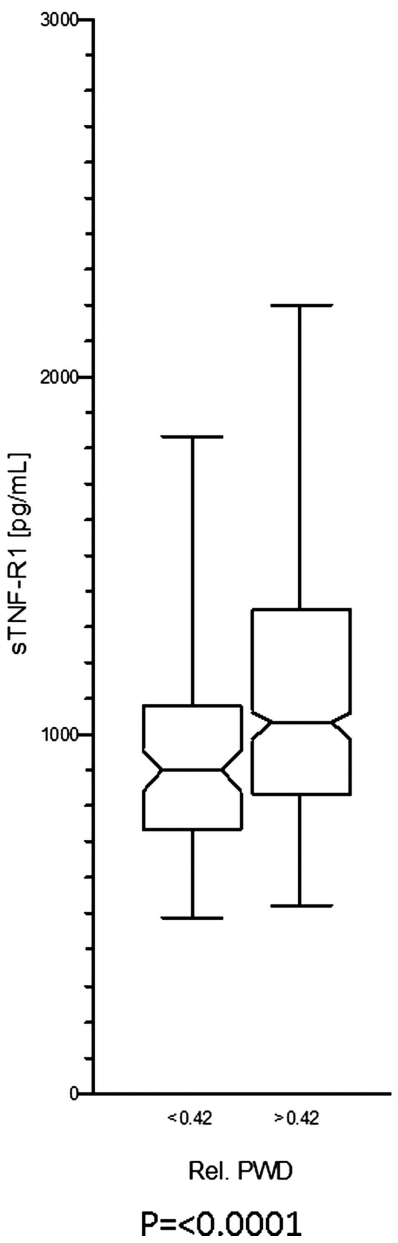

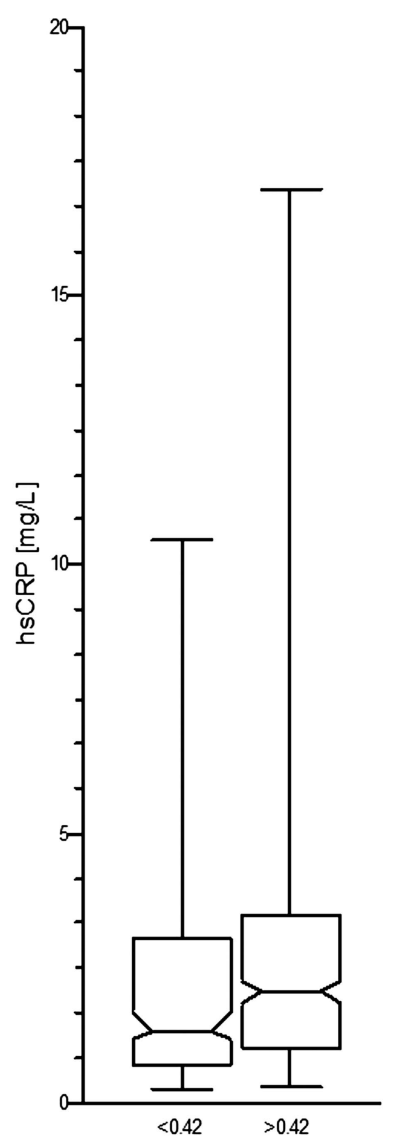

Rel. PMD

$P=0.0003$

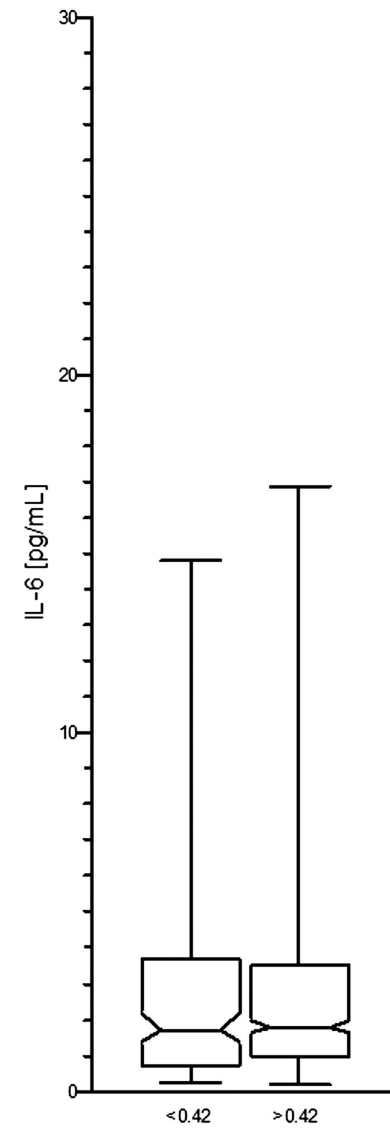

Rel. PWD

$P=0.436$

Figure 2 Box plot comparing inflammation parameters in women with (RPWD<0.42) and without (RPWD>0.42) signs of concentric hypertrophy. Lower and upper whiskers display the $2 \%$ and $98 \%$ quintiles, respectively. Notches display the $95 \% \mathrm{Cl}$ of the median (shortened horizontal line). The box represents participants between $25 \%$ and $75 \%$ quintiles. $p$ Values refer to group comparison (RPWD $<0.42$ and RPWD $>0.42$ ) by means of a Mann-Whitney $U$ test. hsCRP, high-sensitivity $C$ reactive protein; IL-6, interleukin 6; RPWD, relative posterior wall dimension of the left ventricle; sTNF-R1, soluble tumour necrosis factor- $\alpha$ receptor 1 .

appeared distinctly lower than in the unadjusted analyses (table 3). However, the effects were weak, which is especially obvious when the lower confidence limit is considered. Again, participants with signs of concentric remodelling had a higher CRP level in both sexes (figures 1 and 2).

\section{Interleukin 6}

Distributions of IL-6 and hsCRP showed a similar pattern with mainly low blood levels (see online supplementary figure A1). According to the large CIs of the regression analysis, the IL-6 levels were not related to the considered structural parameters (table 4) in men and women. After covariate adjustment the estimates declined, leading to negligible effect sizes. In the same line, IL-6 was not notably associated with the functional parameter of EF in men or women. Participants with echocardiographic signs of concentric hypertrophy and without such indications showed almost identical IL-6 blood levels (figures 1 and 2).

\section{Longitudinal association of inflammation and echocardiographic parameters}

In the longitudinal analysis, we found a slight association of sTNF-R1 and LVDD in women in the univariate $(1.5 \mathrm{~mm} / 1000 \mathrm{pg} / \mathrm{mL}, 95 \%$ CI 0.1 to 2.8$)$ and multivariate models $(1.7 \mathrm{~mm} / 1000 \mathrm{pg} / \mathrm{mL}, 95 \%$ CI $0.1-3.3)$, which was much lower in men. However, this finding might be due to multiple testing, as there was no overall association of sTNF-R1 with the change of echocardiographic parameters when the results of the mixed models are taken into account. All other regression analyses of change in echocardiographic parameters depending on sTNF-R1, IL-6 and hsCRP revealed only minimal, clinically negligible associations (tables 2-4).

\section{Sensitivity analyses}

The performance of a complete case analysis led to higher effect estimates and significant results in few instances (see online supplementary tables A1-3), which might be mainly due to bias driven by missing values 
and outliers. The exclusion of participants with chronic diseases associated with inflammation was not related to relevant alterations of effect estimates (see online supplementary tables A4-6).

\section{DISCUSSION AND LIMITATIONS}

We found minor associations of plasma sTNF-R1 with PWD and LADS in men, and IVSD in women, while plasma hsCRP was slightly associated with LVM, PWD and IVSD in female participants. In the longitudinal analyses no relevant associations could be deduced from our data. In summary this reflects only a weak association of systemic inflammation as measured by plasma levels with structural echocardiographic parameters of ventricular hypertrophy and atrial size. ${ }^{27}$ However, LVM and the size of the left atrium were both reported as being independently associated with hospitalisation and death, respectively. ${ }^{28}$ Owing to the exclusion of participants with major cardiac diseases, these associations might be driven by an endogenous inflammation that was independent of myocardial performance and blood pressure, but was probably due to causes such as age, infectious diseases or chronic inflammatory diseases.

The observed unadjusted cross-sectional association between cardiac mass and sTNF-R1 in men, which was weaker in women, is partly consistent with Takei $e t a l^{9}$ However, the inclusion of possible confounders led to a severe decrease in effect estimates in our study, which might be due to the different ethnic and social background of our collective and, thus, a different impact of confounders. Our unadjusted results also agree with the findings of Roselló-Lletí et $a l^{10}$ who described the sTNF-R1 as the most distinctive factor associated with $\mathrm{LVH}$ among various blood values related to inflammation (TNF, IL-6, interleukin-1ra, sTNF-R1) in a cohort of asymptomatic hypertensive patients, nevertheless estimates in our study were again lower after covariate adjustment and not associated with LVM, but LADS in men. The weak associations found in the longitudinal analysis are explainable by short-term effects of sTNF-R1, which were previously reported in survival analyses. ${ }^{7}$ However, as sTNF-R1 is related to a wide range of inflammation parameters, further inflammatory mechanisms and interactions are likely to be substantial in humans. ${ }^{29}$ We found no relevant correlation of sTNF-R1 with the functional parameter of EF. It is possible that the heart might sustain its function by adapting to alterations in the myocardial pattern. Additionally, the EF is characterised by high intrarater and inter-rater variability ${ }^{30}$ which limits the significance of $\mathrm{EF}$ as a parameter for statistical analyses. We failed to confirm additional associations of sTNF-R1 in the longitudinal analyses and, thus, we could not attribute further predictive value to sTNF-R1.

In women, we found a minimal association of hsCRP with structural echocardiographic parameters, which might reflect a general association of systemic inflammation with cardiac hypertrophy. ${ }^{31}$ Using ECG, Bo $e t a \vec{l}^{22}$ has found evidence that cardiac hypertrophy is a 'status of inflammation' causing increased hsCRP levels, which is consistent with our findings as we failed to find considerable longitudinal associations. Differences in estimates and, more importantly, statistical accuracy between men and women is in contrast to previous cross-sectional findings where similar effect sizes between male and female hypertension patients were found. ${ }^{11}$ It is likely that in our collective further factors such as kidney function and blood pressure (table 1) have a greater impact on ventricular hypertrophy in men than systemic inflammation represented by plasma hsCRP levels.

The associations of echocardiographic parameters representative for LVH with IL-6 were only minimal, and thus, a considerable association of IL- 6 with cardiac hypertrophy was not present in our data, which is consistent with the findings in Takei $e t a .^{9}$

Comparing echocardiographic parameters between baseline and follow-up we found an apparent improvement at follow-up. This finding might be affected by a coincident improvement in cardiovascular health and most importantly blood pressure (see table 1 ) reflecting a possible intervention effect due to study participation.

\section{Limitations}

Apart from our analyses, further unmeasured inflammation parameters might also be associated with cardiac structure and function. ${ }^{33}$ The long interval from baseline to follow-up might conceal short-term effects, which were found in mouse models. ${ }^{34}$ In addition, the interrater and intrarater variability of echocardiography might have contributed to inconsistent results. In this context, differences in measurement methods between baseline and follow-up, for example, interobserver bias due to different examiners at baseline and follow-up, could have biased the results. Nevertheless, to minimise observer bias, a quality assurance process was implemented during data acquisition and reading, including certification of the echocardiographic examination and reader certification. In addition, all echocardiographic examinations were supervised by a senior cardiologist. Concerning inflammation parameters only hsCRP was measured at follow-up, which limits the ability to assess the change in inflammation parameters in more detail. Despite the effort to adjust for potential confounders, there may be residual confounding factors that were not taken into account. From the clinical point of view, pathological findings in echocardiography without symptoms might not be as relevant as actual diseases, but as complex maladies are often difficult to objectify, we focused on these subclinical echocardiographic values. Finally, despite the attempt to treat missing values adequately in the statistical analysis, we cannot fully exclude a weakening or disruption of results because of missing values. 
In conclusion we found a minor cross-sectional association of plasma sTNF-R1 (in both sexes) and plasma hsCRP (in women) with echocardiographic parameters in the general elderly population. Additionally, there are subtle indications of a longitudinal association of sTNF-R1, and hsCRP or IL-6 with LADS. Further studies that survey the changes in cardiac parameters in relation to inflammation, mainly sTNF-R1, over different time intervals and give further insights into the role of inflammation in biochemical processes of heart tissue are now required. ${ }^{35}$

\section{Author affiliations}

${ }^{1}$ Biostatistics and Informatics, Institute of Medical Epidemiology, MartinLuther-University Halle-Wittenberg, Halle/Saale, Germany

${ }^{2}$ Department of Medicine III, Martin-Luther-University Halle-Wittenberg, Halle/Saale, Germany

${ }^{3}$ Division of Cancer Epidemiology, German Cancer Research Centre, Heidelberg, Germany

${ }^{4}$ Institute of Laboratory Medicine, Clinical Chemistry and Molecular Diagnostics, University of Leipzig, Leipzig, Germany

${ }^{5}$ Department of Pneumology and Cardiology, Amper Kliniken AG, Klinikum Dachau, Dachau, Germany

Acknowledgements The authors would like to thank the examiners and probands who made the study possible.

Contributors DM wrote the article and performed all statistical analyses; he carries the responsibility for data analyses and is also the corresponding author. SD, AK, KHG, HL, JT, SN, MR, DT, KW, JH and AF contributed essentially to the organisation of the study and data acquisition. Furthermore $A K, H G, H L, D T, J H$ and KW revised the manuscript critically.

Funding The CARLA study was supported by a grant from the Deutsche Forschungsgemeinschaft as part of the Collaborative Research Centre 598 'Heart failure in the elderly - cellular mechanisms and therapy' at the Medical Faculty of the Martin-Luther-University Halle-Wittenberg, by a grant, from the Wilhelm-Roux Programme of the Martin-Luther-University Halle-Wittenberg, by the Ministry of Education and Cultural Affairs of Saxony-Anhalt, and by the Federal Employment Office.

Competing interests None.

Ethics approval The study was approved by the Ethics Committee of the Medical Faculty of the Martin-Luther-University Halle-Wittenberg and by the State Data Privacy Commissioner of Saxony-Anhalt, and conforms to the principles outlined in the Declaration of Helsinki.

Provenance and peer review Not commissioned; externally peer reviewed.

Open Access This is an Open Access article distributed in accordance with the Creative Commons Attribution Non Commercial (CC BY-NC 3.0) license, which permits others to distribute, remix, adapt, build upon this work noncommercially, and license their derivative works on different terms, provided the original work is properly cited and the use is non-commercial. See: http:// creativecommons.org/licenses/by-nc/3.0/

\section{REFERENCES}

1. Rauchhaus M, Doehner W, Francis DP, et al. Plasma cytokine parameters and mortality in patients with chronic heart failure. Circulation 2000;102:3060-7.

2. Kleinbongard $P$, Schulz R, Heusch $G$. TNF $\alpha$ in myocardial ischemia/ reperfusion, remodeling and heart failure. Heart Fail Rev 2011;16:49-69.

3. Ferranti S de, Rifai N. C-reactive protein and cardiovascular disease: a review of risk prediction and interventions. Clin Chim Acta 2002;317:1-15.

4. Osman R, L'Allier PL, Elgharib N, et al. Critical appraisal of C-reactive protein throughout the spectrum of cardiovascular disease. Vasc Health Risk Manag 2006;2:221-37.
5. Bozkurt B, Mann DL, Deswal A. Biomarkers of inflammation in heart failure. Heart Fail Rev 2010;15:331-41.

6. Valgimigli $\mathrm{M}$, Ceconi $\mathrm{C}$, Malagutti $\mathrm{P}$, et al. Tumor necrosis factor-receptor 1 is a major predictor of mortality and new-onset heart failure in patients with acute myocardial infarction: the Cytokine-Activation and Long-Term Prognosis in Myocardial Infarction (C-ALPHA) Study. Circulation 2005;111:863-70.

7. Ueland T, Kjekshus J, Frøland SS, et al. Plasma levels of soluble tumor necrosis factor receptor type I during the acute phase following complicated myocardial infarction predicts survival in high-risk patients. J Am Coll Cardiol 2005;46:2018-21.

8. Tan J, Hua Q, Li J, et al. Prognostic value of interleukin-6 during a 3-year follow-up in patients with acute ST-segment elevation myocardial infarction. Heart Vessels 2009;24:329-34.

9. Takei Y, Di Tullio MR, Homma S, et al. Soluble tumor necrosis factor receptor 1 level is associated with left ventricular hypertrophy: the Northern Manhattan Study. Am J Hypertens 2009;22:763-9.

10. Roselló-Lletí E, Rivera M, Martínez-Dolz L, et al. Inflammatory activation and left ventricular mass in essential hypertension. $A m \mathrm{~J}$ Hypertens 2009;22:444-50.

11. Iwashima $\mathrm{Y}$, Horio $\mathrm{T}$, Kamide $\mathrm{K}$, et al. C-reactive protein, left ventricular mass index, and risk of cardiovascular disease in essential hypertension. Hypertens Res 2007;30:1177-85.

12. Melendez GC, McLarty JL, Levick SP, et al. Interleukin 6 mediates myocardial fibrosis, concentric hypertrophy, and diastolic dysfunction in rats. Hypertension 2010;56:225-31.

13. Carpena N, Roselló-Lletí E, Calabuig JR, et al. MMP-2 and sTNF-R1 variability in patients with essential hypertension: 1-year follow-up study. ISRN Cardiol 2012;2012:501894.

14. Torre-Amione G, Kapadia S, Lee J, et al. Tumor necrosis factor and tumor necrosis factor receptors in the failing human heart. Circulation 1996;93:704-11.

15. Chizzolini C, Dayer J, Miossec P. Cytokines in chronic rheumatic diseases: is everything lack of homeostatic balance? Arthritis Res Ther 2009;11:246.

16. Ferrari $\mathrm{R}$, Bachetti $\mathrm{T}$, Confortini $\mathrm{R}$, et al. Tumor necrosis factor soluble receptors in patients with various degrees of congestive heart failure. Circulation 1995;92:1479-86.

17. Nilsson L, Szymanowski A, Swahn E, et al. Soluble TNF receptors are associated with infarct size and ventricular dysfunction in ST-elevation myocardial infarction. PLOS ONE 2013:8:e55477.

18. Safranow K, Dziedziejko V, Rzeuski R, et al. Plasma concentrations of TNF- $\alpha$ and its soluble receptors sTNFR1 and sTNFR2 in patients with coronary artery disease. Tissue Antigens 2009;74:386-92.

19. Greiser KH, Kluttig A, Schumann B, et al. Cardiovascular disease, risk factors and heart rate variability in the elderly general population: design and objectives of the CARdiovascular disease, Living and Ageing in Halle (CARLA) Study. BMC Cardiovasc Disord 2005;5:33

20. Rickham PP. Human experimentation. Code of Ethics of the World Medical Association. Declaration of Helsinki. BMJ 1964;2:177.

21. Tiller D, Russ M, Greiser $\mathrm{KH}$, et al. Prevalence of symptomatic heart failure with reduced and with normal ejection fraction in an elderly general population-the CARLA study. PLOS ONE 2013;8:e59225.

22. Teichholz LE, Kreulen T, Herman MV, et al. Problems in echocardiographic volume determinations: echocardiographicangiographic correlations in the presence of absence of asynergy. Am J Cardiol 1976;37:7-11.

23. Lang RM, Bierig M, Devereux RB, et al. Recommendations for chamber quantification. Eur J Echocardiogr 2006;7:79-108.

24. Lang RM, Bierig M, Devereux RB, et al. Recommendations for chamber quantification: a report from the American Society of Echocardiography's Guidelines and Standards Committee and the Chamber Quantification Writing Group, Developed in Conjunction with the European Association of Echocardiography, a Branch of the European Society of Cardiology. $J$ Am Soc Echocardiogr 2005;18:1440-63.

25. Glymour MM, Weuve J, Berkman LF, et al. When is baseline adjustment useful in analyses of change? An example with education and cognitive change. Am J Epidemiol 2005;162:267-78.

26. Donders ART, van der Heijden GJ, Stijnen T, et al. Review: a gentle introduction to imputation of missing values. J Clin Epidemiol 2006:59:1087-91.

27. Simek CL, Feldman MD, Haber HL, et al. Relationship between left ventricular wall thickness and left atrial size: comparison with other measures of diastolic function. J Am Soc Echocardiogr 1995;8:37-47.

28. Zile MR, Gottdiener JS, Hetzel SJ, et al. Prevalence and significance of alterations in cardiac structure and function in patients with heart failure and a preserved ejection fraction. Circulation 2011;124:2491-501.

29. Clendenen TV, Koenig KL, Arslan AA, et al. Factors associated with inflammation markers, a cross-sectional analysis. Cytokine 2011;56:769-78. 
30. Dittoe N, Stultz D, Schwartz BP, et al. Quantitative left ventricular systolic function: from chamber to myocardium. Crit Care Med 2007;35:S330-9.

31. Mehta SK, Rame JE, Khera A, et al. Left ventricular hypertrophy, subclinical atherosclerosis, and inflammation. Hypertension 2007:49:1385-91.

32. Bo $\mathrm{S}$, Mandrile $\mathrm{C}$, Milanesio $\mathrm{N}$, et al. Is left ventricular hypertrophy a low-level inflammatory state? A population-based cohort study. Nutr Metab Cardiovasc Dis 2012;22:668-76.
33. Pai JK, Pischon $\mathrm{T}$, Ma J, et al. Inflammatory markers and the risk of coronary heart disease in men and women. $N$ Engl $J$ Med 2004;351:2599-610.

34. Prineas RJ, CRBH. The Minnesota code manual of electrocardiographic findings. Standard procedures for measurement. Boston: John Wright PSB.

35. Kinugawa T, Kato M, Yamamoto K, et al. Proinflammatory cytokine activation is linked to apoptotic mediator, soluble Fas level in patients with chronic heart failure. Int Heart J 2012;53:182-6. 